\title{
Quality of life of women with polycystic ovarian syndrome
}

\author{
Prabha Dey* \\ Principal, College of Nursing, Rajendra Institute of Medical Sciences, RIMS, Ranchi, Jharkhand, India
}

Received: 23 May 2018

Accepted: 26 May 2018

\section{*Correspondence:}

Dr. Prabha Dey,

E-mail: prabhadey@rediffmail.com

Copyright: $\odot$ the author(s), publisher and licensee Medip Academy. This is an open-access article distributed under the terms of the Creative Commons Attribution Non-Commercial License, which permits unrestricted non-commercial use, distribution, and reproduction in any medium, provided the original work is properly cited.

\section{ABSTRACT}

Background: Polycystic ovary syndrome (PCOS), also known as hyper androgenic anovolation (HA or SteinLeventhal syndrome) is a well-recognised and common condition that causes considerable morbidity. The objective of the present study was to find out the quality of life of women with polycystic ovarian syndrome.

Methods: Patients with PCOD diagnosed clinically at out patients department were selected for the study. SF 36 was applied to find out the Quality of life of women with polycystic ovarian syndrome.

Results: A total of 84 patients were participated and $75 \%$ of the sample were student, $56.7 \%$ were graduate and $86.7 \%$ were non-vegetarian. The mean height of the sample was $155 \pm 4.81$ centimeters. The mean weight of sample was $59.35 \pm 6.63 \mathrm{kgs}$ and BMI mean was $24.70 \pm 3.47$. Among $35 \%$ the duration of diagnosis was less than one year and for $65 \%$ it was more than one year. Means of the all sub set scores, across shorter and longer duration of being diagnosed as PCOD were significantly same on $t$ test.

Conclusions: Measured by SF 36, women with poly cystic ovarian disease/symptoms are suffering from significantly lowered quality of life, but independent of their duration of illness.

Keywords: Polycystic ovarian syndrome, PCOD, Quality of life

\section{INTRODUCTION}

Polycystic ovary syndrome (PCOS), also known as hyper androgenic anovolation (HA or Stein-Leventhal syndrome) is a well-recognised and common condition that causes considerable morbidity.

It comprises a group of signs and symptoms like anovolation (oligoamenorrhea or amenorrhoea) and hyperandrogenism (usually hirsutism, acne, and sometimes alopecia. ${ }^{1}$ It can lead to significant reduction in the quality of life, infertility can cause the tension within the family, altered self-perception, and problem at work. $^{2-4}$

PCOS is frequently diagnosed during adolescence and may be increasing in prevalence secondary to the recent trend of increasing obesity among teenagers. There is increasing evidence that these women are also at increased risk later in life for cardiovascular and metabolic disease, early treatment may prevent disease progression. $^{5}$

Barry et al, conducted a systematic review and metaanalysis and revealed higher and anxiety and depression scores in the participants with PCOS, whereas lower BMI tended to have slightly lower anxiety and depression scores. ${ }^{6}$

With the assumption, that the quality of life affected by a polycystic ovary, and quality of life depends on various other factors like age, occupation, support system and severity of illness; we plan this study to identify the level of quality of life related to physical and psychological health among women with polycystic ovarian syndrome (PCOS). 


\section{METHODS}

The present study was conducted in selected institutions of SOA University area of, Bhubaneswar. For the research study, the research problem was approved by the research committee. Prior permission was obtained from our dean of SUM Nursing College, Khandagiri, Bhubaneswar, Odisha. All consenting patients diagnosed as PCOD, by treating gynecologist attending OPD were included for the study. The investigator conducted face to face interview with the subjects in the study area by using the structured interview schedule. Interview will be conducted between $9 \mathrm{am}-5 \mathrm{pm}$ depending upon the availability of subjects. Individual participant had the right to walk away from the study without assigning any reason to the investigator. The anonymity of the participants was ensured, and confidentiality of the data was maintained.

\section{Tools}

\section{Health related quality of life (HRQoL)}

It is a multidimensional, questionnaires that encompasses physical, psychological and social aspect that associate with the particular disease or its treatment. ${ }^{7,8}$ There are generic questionnaires exist to measure HRQoL, such as the SF-36, it includes "Physical Function (PH), Bodily Pain (BP), Vitality (VT), Social Functioning (SF) Role Emotion (RE), and Mental Health (MH)", they may not be sensitive enough to measure the changes in specific illness as they were designed to measure health status across a wide variety of disease. ${ }^{9}$

There were 25 questions of SF-36 health status questionnaire followed with six domains such as physical function consists of 10 , bodily pain 2 , vitality 4 , social function 2, role emotion 3 and mental health 4 questions. Scoring was done with Likert scale as ' $0=$ not at all, $1=$ rarely, $2=$ often, and $3=$ always.

\section{Statistical analysis}

The data was analysed by using descriptive statistics like frequency distribution, percentage, Mean and standard deviation and Karl Pearson's coefficient correlation and inferential statistics like Chi squire test to find the association of health-related questionnaires with sociodemographic variables and practice with sociodemographic variables.

\section{RESULTS}

A total of 84 patients were included for the study, the categorical distribution of socio demographic variables has been shown in Table 1. The Age category was maximum $31.7 \%$ for 26-31 years age range, occupationally $75 \%$ of the sample was student and remainder $25 \%$ were employed. Most of the sample
$56.7 \%$ was graduate and $61.7 \%$ of sample was belonging to nuclear family and $86.7 \%$ were non-vegetarian.

Table 1: Description of samples according to sociodemographic variables.

\begin{tabular}{|c|c|c|c|}
\hline Sample & Characteristics & Frequency & Percent \\
\hline \multirow{4}{*}{ Age (years) } & $<20$ yrs & 18 & 30.0 \\
\hline & $21-25 \mathrm{yrs}$ & 12 & 20.0 \\
\hline & $26-30 \mathrm{yrs}$ & 19 & 31.7 \\
\hline & $31-35$ yrs & 11 & 18.3 \\
\hline \multirow{2}{*}{ Occupation } & Student & 45 & 75.0 \\
\hline & Employed & 15 & 25.0 \\
\hline \multirow{4}{*}{$\begin{array}{l}\text { Education } \\
\text { status }\end{array}$} & Up to high school & 10 & 16.7 \\
\hline & Intermediate & 7 & 11.7 \\
\hline & Graduate & 34 & 56.7 \\
\hline & Post graduate & 9 & 15.0 \\
\hline \multirow{2}{*}{$\begin{array}{l}\text { Types of } \\
\text { family }\end{array}$} & Nuclear family & 37 & 61.7 \\
\hline & Joint family & 23 & 38.3 \\
\hline \multirow{2}{*}{$\begin{array}{l}\text { Types of } \\
\text { diet }\end{array}$} & Vegetarian & 8 & 13.3 \\
\hline & Non- vegetarian & 52 & 86.7 \\
\hline \multirow{4}{*}{$\begin{array}{l}\text { Years since } \\
\text { diagnosed } \\
\text { PCOD }\end{array}$} & One year & 21 & 35.0 \\
\hline & $2-3$ years & 26 & 43.3 \\
\hline & $4-5$ years & 6 & 10.0 \\
\hline & $>5$ years & 7 & 11.7 \\
\hline \multirow{5}{*}{$\begin{array}{l}\text { Problems } \\
\text { associated } \\
\text { with } \\
\text { menstrual } \\
\text { cycle }\end{array}$} & Less than normal & 14 & 23.3 \\
\hline & Long duration & 25 & 41.7 \\
\hline & $\begin{array}{l}\text { Excessive cyclic } \\
\text { bleeding }\end{array}$ & 17 & 28.3 \\
\hline & Excessive & & \\
\hline & $\begin{array}{l}\text { Interamenstrual } \\
\text { bleeding }\end{array}$ & 4 & 6.7 \\
\hline \multirow{2}{*}{$\begin{array}{l}\text { Problems } \\
\text { associated } \\
\text { with } \\
\text { beauty* }\end{array}$} & $\begin{array}{l}\text { One category of } \\
\text { problem }\end{array}$ & 47 & 78.3 \\
\hline & $\begin{array}{l}\text { More than one } \\
\text { category of } \\
\text { problem }\end{array}$ & 13 & 21.7 \\
\hline
\end{tabular}

*Acne (pimples on the face), Alopecia (loss of hair), Hirsutism, Excessive weight gain.

The BMI of the sample was calculated, and it was overweight for $48.3 \%$ and normal weight for remaining $51.7 \%$. The duration of diagnosis as PCOD was less than one year was $35 \%$ and more than one year was remaining $65 \%$ (2-3 years $=43.3 \%, 4-5$ years $=10 \%$, and above five years it was $11.7 \%$ ). Problems associated with menstrual cycle, such as Less than normal bleeding was found among $23.3 \%$, whereas long duration haven't menstrual cycle was $41.7 \%$, excessive cyclic bleeding was $28.3 \%$ and excessive Interamenstrual bleeding was 6.7\% (Table $1)$.

Table 2: Mean and range of clinical variables of complete sample.

\begin{tabular}{|llll|}
\hline & Min & Max & Mean \pm SD \\
\hline Height $(\mathrm{cm})$ & 150.00 & 162.00 & $155 \pm 4.81$ \\
\hline Height $(\mathrm{m})$ & 1.50 & 1.62 & $1.55 \pm 0.04$ \\
\hline Weight $(\mathrm{kg})$ & 50.00 & 66.00 & $59.36 \pm 6.63$ \\
\hline BMI $\left(\mathrm{kg} / \mathrm{m}^{2}\right)$ & 19.10 & 29.30 & $24.70 \pm 3.47$ \\
\hline
\end{tabular}


The mean height of the sample was $155 \pm 4.81 \mathrm{~cm}$. The mean weight of sample was $59.35 \pm 6.63 \mathrm{kgs}$ and BMI mean was $24.70 \pm 3.47\left(\mathrm{~kg} / \mathrm{m}^{2}\right)$ (Table 2).

For the comparison of SF 36 subset across shorter and longer duration of PCOD diagnosis, the shorter duration consisted upto one year $(\mathrm{n}=21)$ and longer duration defined as more than one year $(n=39)$. Means of the all sub set scoring across in between shorter and longer duration of being diagnosed as PCOD. The both groups showed compromised QOL but there was there was no statistically significant difference (Table 3).

Table 3: Comparison of SF 36 subset across shorter and longer duration of PCOD diagnosis.

\begin{tabular}{|c|c|c|c|c|c|}
\hline & Years of diagnosis & Mean+SD & $\mathrm{t}$ & df & p value \\
\hline \multirow{2}{*}{ Physical function } & Over one year (39) & $21.30 \pm 4.04$ & \multirow{2}{*}{-0.484} & \multirow{2}{*}{58} & \multirow{2}{*}{0.630} \\
\hline & Upto one year (21) & $21.80 \pm 3.37$ & & & \\
\hline \multirow{2}{*}{ Bodily pain } & Over one year (39) & $3.23 \pm 2.00$ & \multirow{2}{*}{-0.828} & \multirow{2}{*}{58} & \multirow{2}{*}{0.411} \\
\hline & Upto one year (21) & $3.66 \pm 1.82$ & & & \\
\hline \multirow{2}{*}{ Vitality } & Over one year (39) & $5.33 \pm 2.74$ & \multirow{2}{*}{-0.840} & \multirow{2}{*}{58} & \multirow{2}{*}{0.404} \\
\hline & Upto one year (21) & $6.00 \pm 3.25$ & & & \\
\hline \multirow{2}{*}{ Social functioning } & Over one year (39) & $2.71 \pm 1.46$ & \multirow{2}{*}{-0.217} & \multirow{2}{*}{58} & \multirow{2}{*}{0.829} \\
\hline & Upto one year (21) & $2.80 \pm 1.72$ & & & \\
\hline \multirow{2}{*}{ Role emotion } & Over one year (39) & $4.92 \pm 2.06$ & \multirow{2}{*}{0.031} & \multirow{2}{*}{58} & \multirow{2}{*}{0.975} \\
\hline & Upto one year (21) & $4.90 \pm 2.40$ & & & \\
\hline \multirow{2}{*}{ Mental health } & Over one year (39) & $5.05 \pm 1.63$ & \multirow{2}{*}{-1.079} & \multirow{2}{*}{58} & \multirow{2}{*}{0.285} \\
\hline & Upto one year (21) & $5.76 \pm 3.47$ & & & \\
\hline
\end{tabular}

\section{DISCUSSION}

Existing research should be reviewed and analyzed with special reference to the knowledge and practice regarding PCOS and prevention of complication among women. Future studies on this aspect will help to identify the common myths that the people are having regarding cultural taboos related to PCOS. Research studies can be conducted to rule out the various misconceptions of the peoples regarding PCOD. Nursing research will help to know the nurse role in developing the practice related to PCOD prevention among young women.

However, present results differ from studies conducted mostly in western countries, showing a positive association between excess weight and reduction in the mental aspects of HRQOL. ${ }^{10,11}$ Given that cultural and social circumstances constitute the concept of ideal body weight, the differences observed in our results could be explained by the variations between Eastern and Western cultures. $^{12}$

Nursing administration should promote the necessary facilities and opportunity for nursing staff to equip themselves with the knowledge of PCOD and its prevention. The nursing administration should support the conduction and participation of the nursing staff in various types of continuing education related to gynecological nursing and its prevention to enhance the nursing skill and knowledge in the area.

Present study showed that women with PCOS, generally scored quite low on HRQOL, a mean score of 43.4 is very low to a maximum possible score of 75 that is equal to $57.8 \%$. However, when grouped as shorter as up to one year and long duration since diagnosis that is more than one year, the both groups were age, height, weight and BMI matched, the both groups were assessed across all domains of health-related quality of life, including vitality (VT), mental health (MH), social functioning (SF), bodily pain (BP) and general health perception (GH). In the present study, women with PCOS had lower scores in five domains of health-related quality of life, of which 3 domains (vitality, mental health, social functioning) were related to mental aspect of healthrelated quality of life; it seems that, similar to results of previous studies, the mental health domain of SF 36 was affected more than the physical domain..$^{13,14}$

Since socio-demographic factors among women with PCOS and controls were comparable; it could be concluded that features associated with PCOS result in decrease in the HRQOL of these women. Results of the current study demonstrated that consequences of excess weight on the physical aspects of HRQOL varied between women with PCOS and healthy controls, results in agreement with those of a study that reported co morbidity of obesity had a greater impact on HRQOL. ${ }^{15}$

With early diagnosis and adequate information, individuals can prevent serious complications and minimize the distressing symptoms that accompany PCOS. However, in this index study there was no difference were found in lower QoL in between longer and shorter duration of illness (Table 3). 
With the great prevalence of PCOS, and the lack of knowledge in the population, many women are set up to struggle with this mysterious disease while feeling completely alone. Women with PCOS have also complained that they have received "less than optimal" information about the syndrome, including its short and long-term implications. It has been also noticed that some of them are really frustrated with her life problems with menstrual cycle and duration of illness. Because of these facts and other research, it had been suggested that information programs for PCOS would be very beneficial, especially in the relation to Quality of Life. ${ }^{16}$

\section{CONCLUSION}

Women with poly cystic ovarian disease / symptoms are suffering from significant impaired quality of life as measured by HRQOL (SF 36), the impairment was found to be independent of their duration of illness.

Funding: No funding sources

Conflict of interest: None declared

Ethical approval: The study was approved by the Institutional Ethics Committee

\section{REFERENCES}

1. Balen A, Homberg R, Frank S. Defining polycystic ovary syndrome. Br Med J. 2009;338:a2968.

2. Sonino N, Fava GA, Mani E. Quality of life of hirsute women. Postgrad Med J. 1993, 69(809):1869.

3. Paulson JD, Haarmann BS, Salerno RL, Asmar P. An investigation of the relationship between emotional maladjustment and infertility. Fertil Steril. 1988, 49(2):258-62.

4. Downey J, Yingling S, McKinney M, Husami N, Jewelewicz R, Maidman J. Mood disorders, psychiatric symptoms, and distress in women presenting for infertility evaluation. Fertil Steril. 1989;52(3):425-32.

5. Dokras A. Cardiovascular disease risk in women with PCOS. Steroids. 2013;78(8):773-6.

6. Barry JA, Kuczmierczyk AR, Hardiman PJ. Anxiety and depression in polycystic ovary syndrome: a systematic review and meta-analysis. Hum Reprod. 2011;26(9):2442-51.
7. Naughton MJ, McBee WL. Health-related quality of life after hysterectomy. Clin Obstet Gynecol. 1997; 40(4): 947-7.

8. Colwell H, Mathias SD, Pasta DJ, Henning JM and Steege JF. A health-related quality of life instrument for symptomatic patients with endometriosis: a validation study. Am J Obstet Gynecol. 1998;179(12):47-55.

9. Streiner DL, Norman G. Health Measurement Scales: A Practical Guide to their Development and Use. $2^{\text {nd }}$ ed, Oxford University Press, Oxford, UK;2000.

10. Benetti-Pinto CL, Ferreira SR, Antunes A Jr, Yela DA. The influence of body weight on sexual function and quality of life in women with polycystic ovary syndrome. Arch Gynecol Obstet. 2015;291(2):451-5.

11. Kozak AT, Daviglus ML, Chan C, Kiefe C, Jacobs $\mathrm{D}$, Liu K. Relationship of body mass index in young adulthood and health-related quality of life two decades later: the Coronary Artery Risk Development in Young Adults Study. Int J Obestet. 2011;35(1):134-41.

12. Grivetti L. Psychology and cultural aspects of energy. Nutr Rev. 2001;59(1):5-s12.

13. Clayton WJ, Lipton M, Elford J, Rustin M, Sherr L. A randomized controlled trial of laser treatment among hirsute women with polycystic ovary syndrome. Br J Dermatol. 2005;152(5):986-92.

14. Coffey S, Mason H. The effect of polycystic ovary syndrome on health-related quality of life. Gynecol Endocrinol. 2003;17(5):379-86.

15. Coffey S, Bano G, Mason HD. Health-related quality of life in women with polycystic ovary syndrome: a comparison with the general population using the Polycystic Ovary Syndrome Questionnaire (PCOSQ) and the Short Form-36 (SF-36). Gynecol Endocrinol. 2006;22(2):80-6.

16. Ching HL, Burke V, Stuckey BG. Quality of life and psychological morbidity in women with polycystic ovary syndrome: body mass index, age and the provision of patient information are significant modifiers. Clil Endocrinol. 2007;66(3):373-79.

Cite this article as: Dey P. Quality of life of women with polycystic ovarian syndrome. Int J Reprod Contracept Obstet Gynecol 2018;7:2586-9. 